\title{
On the Rearing and Breeding of Gammarus in Laboratory Conditions.
}

\author{
By \\ E. W. Sexton, F.L.S. \\ Research Assistant at the Plymouth Laboratory. \\ With 1 Figure in the Text.
}

THE following paper has been prepared in the hope that it will be of assistance to anyone desirous of carrying out experiments on Heredity with Gammarus chevreuxi. This Amphipod has been the subject of study at the Plymouth Laboratory since 1912, and the following notes are chiefly concerned with rearing and breeding it under Laboratory conditions.

Details of the work will be found in the papers mentioned in the bibliography on page 54 .

\section{The Genus Gammarus.}

Gammarus, ${ }^{*}$ the earliest established genus of the Amphipoda, has a very extended range and comprises an unusually large number of species. Its representatives are found widely distributed; in the sea, living either on the shore under stones or seaweed, like G. marinus, or leading a more pelagic life, like G. locusta; in the brackish waters of salt marshes and tidal in'ets as e.g. G. duebenii; in fresh-water streams and in lakes up to a height of $4000 \mathrm{ft}$. above sea-level, like G. pulex; in the cold of the Arctic regions; and even in hot springs.

The species named above are common in British waters, and all have proved very hardy and easy to keep in captivity. In addition to these, numerous other species occur all round our coasts, some of them already known to science, others as yet undescribed, all or any of which would well repay collecting and investigation. The species more particularly dealt with here is a brackish-water form, and was chosen partly because animals of the brackish fauna are able to endure greater variation of conditions than either those from the sea or from fresh water, and partly because this species developed a power of mutation in advance of the other species then under observation. I have little doubt, however, p. 460 .

* For generic characters, see Stebbing, 1906, Das Tierreich, Vol. 21: Amphipoda, NEW SERIEs. - vol xy. No. 1. February, 1928. 
that this power is latent in other Amphipod species and that a closer study will discover its presence. Two or three instances in proof of this statement may be mentioned : the Nowhite-eye mutation which developed in $G$. chevreuxi was also seen in $G$. pulex and $G$. duebenii in the Laboratory ; a Red-eye mutation was once seen in G. pulex; and another variation, the Irregular Coloured-eye, was found in another Amphipod genus, Apherusa. A specimen of A. ovalipes Norm. and Scott, captured in the open sea, had the normal round eye on the left side, but the right eye was wedge-shaped and only half the width of the other.

The species of Gammarus vary to a great degree inter se, in size, in the number and length of the growth stages to sexual maturity, in the age at which maturity is reached, in the length of the reproductive periods, and in the number and size of the young in a brood.

In all, seven species have been bred for several generations in the Laboratory under practically the same cultural methods. Before proceeding to describe these methods it will be well for the better understanding of a Gammarus and its needs to give a brief account of the structure of the animal. The description is taken from a Gammarus chevreuxi, that being the species on which most work has been done.

\section{Description of Gammarus chevreuxi.}

The subjoined diagram (Fig. 1) of a male of this species shows the essential points of the external structure of a Gammarus, with the exception of the mouth-parts and the eye, which are omitted in order to avoid confusing the outlines of the proximal joints of the antennæ.

The body is elongate and laterally compressed, and consists of head, peræon, and pleon. The head, with which the first thoracic segment is fused, carries the two pairs of antennæ, the two eyes, one on each side above the bases of the antennæ, and the mouth-parts. The percoon consists of seven segments, each segment provided with a pair of legs, the 2 nd to the 7 th bearing the gills in addition to these appendages. In the female the incubatory lamellæ of the brood-pouch are attached to segments $2-5$. The pleon is composed of six segments and the telson, each segment with a pair of appendages, the 6th carrying the telson on its posterior margin.

Taking in order the different parts of the body and their functions they are as follows :-

First or Upper Antenna, each consisting of a 3-jointed peduncle with a long many-jointed primary flagellum and a much shorter accessory flagellum. The length, i.e. the number of joints, in the latter is frequently used as a specific character, e.g. an adult of $G$. locusta has about 8 joints in the accessory flagellum, $G$. pulex $4, G$. chevreuxi $5, G$. duebenii 6 , and 
so on, but this character, though useful, is unsafe unless it is certain that one is dealing with adult animals which have attained their full growth. In the antennal flagella new joints are developed at each growthstage; in $G$. chevreuxi, for instance, the primary flagellum is 4-jointed

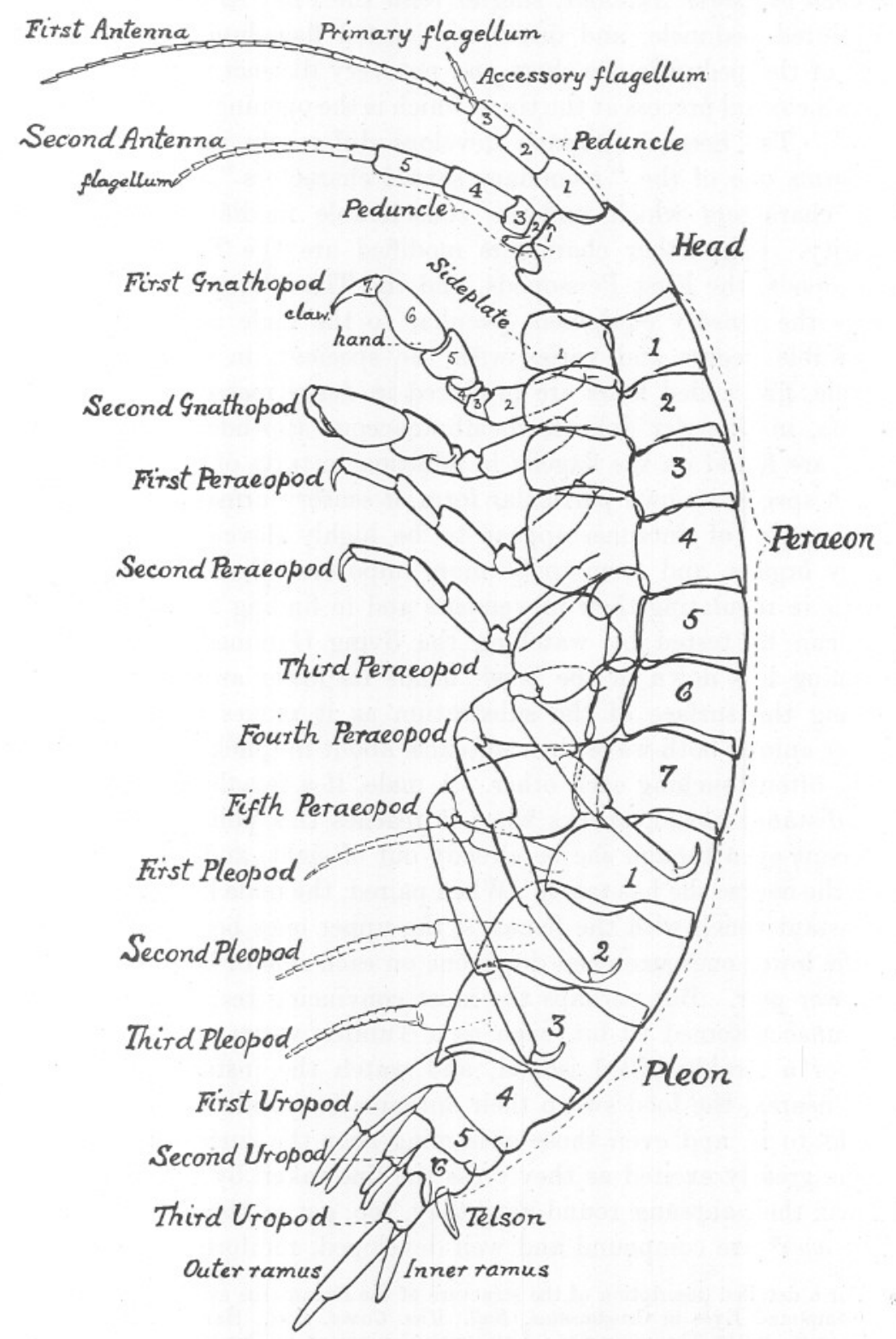

FIG. 1.-Diagrammatic drawing of the male of Gammarus chevreuxi. $\quad \times 10$. 
on hatching, the accessory 2 -jointed. By the time sexual maturity is reached, the number has increased in the female to 20 in the one, and 4 in the other; in the male to 28 and 5 ; and the number continues to increase until the maximum growth of the species is attained.

Second or Lower Antennce, shorter than the First Antennæ, each with a 5-jointed peduncle, and one many-jointed flagellum. The first two joints of the peduncle are short and not very distinct; the second one carries a conical process at the tip of which is the opening of the " antennal gland." The Second Antenna develops differently in the two sexes, and forms one of the "secondary sexual characters" of the male, i.e. those characters which undergo considerable modification at sexual maturity. (The other characters modified are the First and Second Gnathopods, the First Peræopods, and the Third Uropods.) In all the species the sensory equipment peculiar to the male is developed to a remarkable degree and varies with the species; in G. chevreuxi, for example, fine coiled hairs are produced in dense masses on the second antenna, in $G$. pulex delicate membranaceous appendages called "calceoli " are found on the flagella in addition to tufts of setæ, and so on, to each species its own particular form of sensory armature.

Both pairs of antennæ appear to be highly developed tactile and sensory organs, and seem to be more important than the eyes to the animals in regulating their movements and in finding food. This statement can be tested by watching the living Gammarus. An animal swimming low down in the bowl, bends its lower antennæ and keeps touching the surface of the substratum as it moves along; meeting another animal both wave their antennæ about in quick fluttering movements, often touching each other. A male, if a female crosses its path some distance ahead, checks when it reaches this point, turns at once in pursuit even though she be already out of sight, and follows directly along the course she has taken. When paired, the male keeps its antennæ in constant touch with the female's, the upper ones bent to touch hers, and the lower ones stretched down one on each side of her head to reach her lower pair. But perhaps the most convincing test of all is to give some unaccustomed tit-bit, such as a Tubifex worm, a soaked wheatgrain or a freshly killed isopod, and watch the instantaneous effect. Those nearest the food sweep their antennæ from side to side, and dart straight to it, and even those swimming near the surface of the water become greatly excited as they cross the line taken by the falling food, and lash their antennæ round until they, too, get on the right track.

The eyes* are compound and well developed, reniform in shape, with

* For a detailed description of the structure of the Gammarus eye, see Parker, 1891, The Compound Eyes in Crustaceans, Bull. Mus. Comp. Zool., Harvard, XXI, No. 2 ; and Bennitt, 1924, The migration of the retinal pigment in Crustaceans, Journ. Exp. Zool., Vol. 40, Philadelphia. 
the corneal cuticle smooth and not facetted (see also p. 45). The superficial aspect of the eye, or ommateum, of the wild G. chevreuxi presents the appearance of a chalky-white reticulation with the ommatidia showing as round black spots in the meshes of the network. The ommateum is composed of a number of ommatidia arranged in regular rows, the number increasing at the growth-stages and rising from 10 to 12 in the newly hatched to 70 or 80 in the adult. Each ommatidium possesses, under the thin, transparent, corneal cuticle, a layer of hypodermic cells. Below the hypodermic layer come the crystalline cones, one pair to each ommatidium, the two forming an oval lens. Immediately below the cones, is the rhabdome, a transparent slender rod composed of four elongated segments. The rhabdome is surrounded by five cells, four large and one small, known as the retinular cells, the distal ends of which extend also around the sides of the cone. According to Bennitt (1924) the proximal ends of these retinular cells pass as nerve fibres into the optic ganglion. The retinular cells are deeply pigmented, the pigment in the wild Gammarus being black, and in some of the mutations red. Between the ommatidia lie the superficial accessory-pigment cells, which contain the white pigment of the eye.

Mouth-parts.-These consist of an Upper Lip attached to the epistome, and a Lower Lip at the entrance to the œsophagus: the Mandibles, each composed of a basal joint and a 3 -jointed palp, the basal joint produced to a dentate cutting-edge with an accessory plate on the inner side, a spine row, and a denticulate tubercle or molar: the 5-jointed First Maxilla, each with the 1st and 3rd joints expanded to form an inner plate carrying setæ and an outer plate with serrate spines, and a 2 -jointed palp made up of the 4th and 5th joints; the 3 -jointed Second Maxilla with the 1st and 3rd joints expanded into inner and outer plates fringed with setæ; and one pair of 7 -jointed Maxillipeds, with the 1st or basal joints fused, the 2nd and 3rd expanded into inner and outer plates, and the 4 th to the 7 th joints forming the palps.

Percon.-The peræon contains the heart in a pericardiac sinus, the hepato-pancreatic tubes, and the reproductive organs with the oviducts in the female opening on each side of the 5th segment, and the testes in the male opening on the 7 th segment.

Incubatory lamella.- The brood-pouch of the female is formed of four pairs of broodplates, or lamellæ, attached to the $2 \mathrm{nd}, 3 \mathrm{rd}, 4 \mathrm{th}$, and 5 th peræon-segments. Several growth-stages (moults) before sexual maturity is reached the broodplates appear, showing first as minute rounded budlike processes which increase in size at each successive moult and develop. hairs along the margins. In the mature female the broodplates are large, the fringing hairs are long and flexible, and can be interlaced in such a 
way as to make a continuous pouch open only at the two ends where the body-width prevents the plates meeting.

The branchial vesicles* or gills are attached by slender stalks to peræonsegments $2-7$, one pair to each segment; they are of simple structure, and leaf-like in shape.

The seven pairs of percoopods are divided into two distinct groups, the first group containing four pairs, the First and Second Gnathopods, and the First and Second Perceopods, all bent forward at the third joint, making an open angle in front; and the hinder group with three pairs, the Third, Fourth, and Fifth Percoopods bent backwards at the third joint, making an open angle behind.

The legs are 7-jointed with the first joint greatly expanded in the form of a thin flat plate, known as the sideplate. In the first group the sideplates are large and deep, overlapping and protecting the broodplates and gills. The fourth and largest differs in shape from the three preceding by having the distal portion produced to nearly twice the width of the upper part; the shape of this sideplate is a useful character for separating the species of a genus. In the hinder group the sideplates are much smaller, and the second joints are articulated to them in such a way as to allow of an extraordinary flexion of the limb. In Peræopods 3 and 4 the lower margin of the sideplate is deeply cleft, forming two lobes and the widely expanded second joint connected only by a very narrow attachment in the cleft, lies with its anterior expansion below the front lobe and its posterior expansion above the hind lobe, an arrangement which enables the leg to be bent almost to a right angle upwards and backwards against the body. When at rest under a leaf or stone the animal turns its hinder peræopods back in this way and thus brings the terminal claws into a position to hook firmly into the leaf or inequalities of the stone.

The First and Second Gnathopods are stronger in the male than in the female. They are used for seizing food, and in mating. Both are subchelate, the expanded 6th joint, known as the "hand" forming with the clawlike terminal joint or " finger," a powerful grasping organ.

Of all the parts of the body, the gnathopods, especially those of the male, are the most subject to modification by growth, and as they are the principal external characters employed in specific distinction, it is important to study all the growth stages, and to note in particular the changes in the shape of the hands and the development of their sensory armature. While it is impossible to mistake the fully adult males of the different species of Gammarus, it is easy enough to confuse the young males and females, and the immature. The structure and position of the

* Sexton, 1913 , p. 545 , a printer's error in line 20 should be deleted from " and densely " to the end of the sentence. 
various sensory spines and setæ will often help in identifying the young stages of any one species.

The Percopods are long and slender, with the terminal joint in the form of a strong curved claw. The sideplates of peræopods 1 and 2 are large and deep; in the hinder pairs the sideplates are short, and the 2nd joints laminarly expanded.

The Pleon consists of two groups of three segments each, and the telson. The segments of the first group are wide and deep, increasing in size from the 1st to the 3rd, with the terga produced laterally into large epimeral plates. Each segment bears a pair of Pleopods, which function as swimmerets and differ in structure from the other appendages. A pleopod is composed of a stout basal joint or peduncle, and two flexible many-jointed rami. The basal joints are provided with coupling-spines by means of which each pair can be hooked together; the rami carry two long plumose swimming-hairs on each joint, the inner ramus in addition being furnished with cleft spines on its first joint. The pleopods beat with a steady rhythmic movement, keeping up a constant current of water over the gills and through the brood-pouch.

The three remaining pleon-segments, sometimes called the urosome, rapidly decrease in size, the 6 th being very small. They are capable of great flexion, and, moving together as one joint, they form a powerful springing or jumping organ. The posterior margins are armed with three groups of spines and setæ, one median and two lateral. The second pair of legs, or uropods, is the shortest, the third the longest. Each uropod consists of a basal joint and two slender rami, beset with spines. The rami of the third pair are broad and fringed in the adult with spines and plumose hairs; the outer ramus is 2 -jointed, the terminal joint very small.

The telson is small and cleft.

Size.-Gammarus chevreuxi is a small species, full-grown males measuring about $11 \mathrm{~mm}$. and full-grown females about $7 \mathrm{~mm}$., the largest recorded being 14.5 and a bare $9 \mathrm{~mm}$. respectively. The measurements are taken from the tip of the rostrum along the dorsal line to the tip of the telson.

The species is easily distinguished (see 1) from the others of the genus by the antennæ, the shape of the fourth sideplate, gnathopods, and third uropod, and particularly by the fine coiled hairs peculiar to the male secondary sexual characters.

Colour.-The body is semi-transparent with the internal organs showing through the thin chitinous cuticle. The normal wild animals are a pale greenish colour, the males yellower than the females, with the antennæ 
banded with brown, and the mouth organs tinged with crimson. The intestine shows as a line down the body, coloured according to the food last eaten ; in the female the dark green masses of the gonads can be seen lying above it in the peræon. The pleon segments have a bright red spot on each side, composed of numbers of red oil globules.

A new mutation has lately arisen in which the body is a translucent. pearly-white, with no trace of colour even in the gonads and eggs of the female.

Growth.-The development of Gammarus and of Amphipods generally may be described as a series of growth-stages definitely marked off the one from the other by moults, i.e. the complete casting of the hard chitinous cuticle (see 11).

The period between moults is short in the immature, and the increase in size considerable at each stage up to the time of sexual maturity. This point is reached when the animal is about half-grown, and from then onwards until it attains the maximum length of the species the moults take place at longer intervals and the increase in size though constant is much more gradual and therefore less noticeable at each stage. After full growth is established the difference between the stages is practically imperceptible and is usually concerned with the cuticle and its outgrowths, the chitin becomes thicker, a few more setæ are developed or slightly modified, and the colour darkens.

The rate of development is affected to a large degree by temperature and to a lesser degree by the seasonal rhythm. Young hatched in the winter months take longer to reach maturity, even though the temperature be raised to summer conditions, than those hatched in the spring and summer.

Sex and Reproduction.-The sexes cannot be distinguished on hatching nor for several stages afterwards, not, indeed, until the animals are approaching maturity.

The newly-hatched Gammarus chevreuxi measures about $1 \mathrm{~mm}$. in length, and resembles the adult in that the full number of the appendages is present. The full number of joints also is present in most of the appendages, as.e.g. in the gnathopods, peræopods, and uropods; but certain structures such as the flagella of the antennæ and the rami of the pleopods, develop new joints at each succeeding stage of growth.

The number of stages from birth to sexual maturity varies with the species. In G. chevreuxi maturity is reached at the eighth stage, and up to the fifth stage it is impossible to distinguish the male from the female by any external character; they are identical in size and form, even to the number of the setæ and spines. In the fifth stage, broodplates are 
present in the female, but being microscopic in size, they are exceedingly difficult to trace. In the sixth stage, however, the difference between the sexes becomes plainly evident, one or two of the coiled hairs peculiar to the male appear on the lower antennæ, and the broodplates of the female can be seen as small oval plates, with rudimentary hairs on the margins.

The age at which sexual maturity is reached depends largely on temperature. In summer the time taken may be only 36 to 40 days; in winter conditions 2,3 , or 4 months may pass before breeding begins.

The male pairs with the female several days before mating takes place, sometimes for as many as 8 or 9 days. During this period the male carries the female, and holds her usually with its second gnathopods, the right-hand claw being inserted under the anterior edge of the tergum of her first peræon-segment, and the left-hand claw turned backwards and inserted under the posterior margin of the fifth segment. Sometimes the male's first gnathopods and first and second peræopods are also brought into action to help steady the female when swimming rapidly, or to assist her in moulting. As soon as the female moults pairing takes place, and mating follows usually at once. The sperm is ejected into the open pouch, and the eggs are then laid directly afterwards, two at a time, one from each oviduct, until the ovaries are emptied. The eggs are held together at first by the secretion which accompanies oviposition. They can only be deposited while the skin is soft and elastic after a moult, and the apertures of the oviducts are open.

Oviposition is still possible up to the third day after moulting, but, should no eggs be laid by that time, the pair usually separate and no further mating can take place until the next reproductive period, and then only after another moult. The number of eggs laid at the first. mating is usually small, rarely reaching 10 ; sometimes these hatch normally, sometimes they are thrown off in a day or two. The number of young in a brood increases as the female grows. The largest brood recorded for $G$. chevreuxi numbered 63 , but this is an exceptional figure, 30 to 40 being a fair average. The female mates at regular periods; the male, however, has no defined mating period, but can fertilise several females in succession. In this species eggs are never deposited unless a male is present. The females breed continuously all the year round, only now and again missing a period until they reach the age of 12 to 18 months, and become too old to lay. Pairing again and again with no results they usually end either by dying in moulting, or by being eaten by the male.

Twenty-six is the highest number of broods recorded so far for one pair, the number of young hatched being as follows : $8,21,39,31,29$, 
missed a period, 27 , two broods* numbering 17 together, $32,39,37,20$, $^{*}$ $39,33,34,29,41,48,42,32,52,43,29,26,29,3$. The female had one brood of 6 with another male, and two batches of eggs which did not develop with a third male, and was then eaten.

The number of young in a brood varies with the species, but the size of the species is no gauge of either the size or the number of young. $G$. chevreuxi is a small species compared with $G$. pulex, yet it produces up to 63 young in a brood, whilst the highest record for $G$. pulex is only 28. The pulex young are much larger, but the difference in the size of the young is not correlated with the species size as might be thought from this example. In $G$. locusta the female is practically identical in measurements with the female $G$. pulex, but her young are minute, much smaller even than those of $G$. chevreuxi, and her average brood numbers from 140 to 150 .

Gammarus chevreuxi was first found in the ditches draining Chelson Meadow, a salt marsh near the mouth of the Plym. The land, reclaimed a little over a century ago, is protected from the tidal waters by an embankment, with the drainage emptying into the Plym at low water by means of sluice-gates. A fresh-water trickle runs in at the upper end of the Meadow, and sea-water occasionally enters over the sluicegates. Several species of Gammarus are found, G. pulex inhabiting the stream, G. duebenii and $G$. chevreuxi the brackish ditches near the embankment.

\section{Cultural Methods.}

The animals are kept in finger-bowls covered with square glass plates to exclude dust and prevent evaporation. We find the most useful size is $13 \mathrm{~cm}$. measured across the top. Glass meat-jars can be used and are cheaper, but finger-bowls are better for the purpose. The rounded sides and bottom prevent the settlement of injurious bacteria or infusorians, and the glass being clear enables one to observe the animals without disturbing them unnecessarily.

The bowls are only half filled, in order to expose as large a surface of water as possible to the air and so provide sufficient oxygen for the animals' needs. This applies more especially to G. chevreuxi and G. pulex, but even the pelagic species such as $G$. locusta which naturally require a far greater amount of oxygen, can also be brought to live in stagnant water, though it may be found necessary at first to give the newlycaptured some sort of air circulation and then gradually to reduce the supply for their young.

* These broods were not examined for some days after extrusion and the number of young found is therefore less than the number hatched. 
Water.-G. chevreuxi in its wild state inhabits brackish water ditches, the salinity of which, affected by the state of the tides and the rainfall, varies from day to day. For Laboratory work we find it better to keep to a constant salinity, and the water used in the experiments has therefore been standardised, one part sea-water to four parts fresh water. The sea-water is brought in from the open sea, beyond the reach of contamination by shore bacteria. Brackish water, however, is not absolutely essential to the culture of this species. It will live equally well in fresh water provided only that the change in conditions be made very gradually and extended over a period of several weeks. All the British Gammarus are hardy creatures, capable of adapting themselves to alterations of environment if, as has just been said, sufficient care is exercised in making the alteration. Three species, the marine $G$. locusta, brackish $G$. chevreuxi, and fresh-water $G$. pulex, which were kept in this Laboratory in different salinities ranging from supersaturated salt water to fresh water, lived and bred equally well in all.

The water in the bowls does not really need changing, although as a matter of practice while the breeding-bowls are under observation it is partly renewed when the broods are hatched. Each brood is given a separate bowl and a little of the water in the parents' bowl is poured off into the brood-bowl, standardised water being then added to both to bring the level right again. Experience has shown that the young do better in a mixture of this kind, and the breeding animals also profit by the change of water. No regular air circulation is needed, but an occasional pipetting of the water with a sterilised pipette is beneficial to them.

Food.-Most Amphipods will devour almost anything in the nature of organic matter from rotting seaweed to dead animals, and Gammarus is no exception to this rule. They do not usually attack living creatures unless they have them at a disadvantage, as for example in the exhausted condition following a moult. In such circumstances a female often falls a victim to the male's voracity. Unfortunately, once a cannibal always a cannibal, and any animal caught in the act must be removed at once from the bowl.

Animal food is much preferred to vegetable, but as it seems almost certain that a flesh diet, apart from the danger of fouling the water, encourages the cannibal instincts, we have given it up in favour of a purely vegetable regime. The food found by experience to be the most suitable is rotted leaves, and preferably elm leaves. The harder leaves of oak and beech are sometimes eaten, but only if it is a choice between them and starvation.

The dead leaves are collected in the autumn after a frost, well dried in a sunny window, and stored for use. When wanted, they are washed 
and soaked in fresh water for a day or two. It is advisable to soak only a small quantity at a time and to change the water at frequent intervals to prevent the formation of slime due to bacterial growth. One mediumsize elm leaf is quite sufficient for a breeding pair. By the time the brood is hatched the leaf will be eaten nearly to a skeleton, only the ribs and some of the soft parts being left. The skeletonised leaf is the best food the young can have, and after a thorough washing it should be given to them and a fresh leaf put in the parent-bowl.

A change of food is sometimes beneficial. Wheat grains soaked for two or three days are eagerly taken; a half-grain is enough to give at a time in addition to the leaf. The hard-boiled yolk of an egg is also acceptable, but proves a costly item when hundreds of Gammarus have to be fed. Green seaweeds such as Ulva and Enteromorpha were given at one time, but their use has been discontinued, owing to the difficulty of getting them free of other Amphipod young.

Light.-The bowls should be kept in ordinary diffused daylight and never exposed to direct sunlight. The Gammarus usually shelter under the leaves, out of the light.

Temperature.-Experimental work has been done on $G$. chevreuxi in temperatures ranging from $70^{\circ}$ to $36^{\circ}$ or $38^{\circ} \mathrm{Fahr}$. Batches of eggs laid on the same day hatched in 8 days at $70^{\circ}$, but took 80 days in the cold. The species breeds all the year round in the ditches, but the rate of development, as would be expected, is greatly retarded by low temperature in the winter months.

Sterilisation.-The greatest care must be exercised when examining the broods to keep the instruments sterilised. The pipette and rubber top should be thoroughly heated after each brood to prevent the risk of a young one creeping into the top and emerging later when another brood is being examined. It is very easy to lose sight of one in this way, as it is semi-transparent and measures only $1 \mathrm{~mm}$. in length, and moves with great rapidity. The glass slip must be sterilised each time as well as the watch glasses into which the young are counted. A very effective steriliser can be made of a large round enamel basin, filled with water deep enough to take a finger-bowl, kept boiling on a tripod over a bunsen burner.

Examination Methods for eye-colour, mutations, etc. As soon as a brood is extruded, the young are picked out with a fine pipette, counted, and if possible examined immediately for eye-colour. It is important in all cases that this should be done at once, because of the heavy mortality usual at the first moult; but in certain instances, such as the Changeling White mutation for example, where the colour alters soon after hatching, the record is of no value unless the examination is done immediately, 
for animals about which there is any doubt cannot be used in the experiments.

For examination, each young one is taken out separately on a glass slide, the water is drained off and the slide held tipped under the microscope 1 in. obj., and the eye uppermost looked at; then the slide is turned quickly, and the other eye examined, colour, irregularity, and spots being noted. The tipping of the slide is for the purpose of keeping the animal as dry as possible, and so preventing its wriggling. Speed is necessary to avoid a prolonged exposure to the air, and a little practice renders it easy to do the work at the rate of ten seconds to each normal young. Anything abnormal, such as malformation, or irregularity of eye, takes a longer time, and as these abnormal ones need even more care than the others, it is well to add a drop of water at intervals to refresh them.

System of Records.-Each experiment has its own distinctive letter or number, and its own series of Record Books. Each breeding pair in an Experiment has a bowl to itself and is given a number, and this number, with the Experiment letter or number preceding it, is marked on a label on the cover, together with the dates on which the bowl is looked at. The details of the daily observations are kept on loose sheets of paper; and include particulars of the derivation of the animals, the dates of matings, moults, oviposition, the date on which the ripening eggs change colour, from dark green to yellow and from yellow to orange, and the date on which the young are extruded. All these details are afterwards entered up for permanent reference in the Record Books.

\section{Mutations in Gammarus chevreuxi.}

The first mutations which arose in this species were connected with the eye, its structure, shape, and colour (see 4 and 6).

The normal eye or ommateum is reniform in shape and convex, with the margin entire (cf. p. 37). It is composed of numerous ommatidia arranged in regular rows, and showing as round coloured spots in a network of white The coloured pigment is contained in deep-seated retinal cells around the bases of the ommatidia ; the white pigment on the other hand is quite superficial. The retinal colour in the wild animal is black, and up to the present time none but black-eyed have ever been found in the ditches, although many thousands have been dredged from time to time and examined for eye-colour. That the black, however, was not a pure black was found by observing the developing embryos of females freshly brought in.

Two sets of females were kept under daily observation, 15 which had laid eggs on January 28th, and 13 with eggs on the 29 th. The incubatory 
period of the first set was 12 days ; that of the second, owing to a drop in the temperature on the 11th day, was 13 days.

One female was taken daily from each set, and the eggs were removed from the pouch and examined under the microscope. The first sign of the eyes appeared on the 9th day. Three to four ommatidia with minute lenses were seen, and the margin of the ommateum could be traced. The pigment was bright red. By the next day the colour had altered a little and deepened to a darker shade of red, the shape of the ommateum was much clearer and the number of the ommatidia had increased to 8 , or to 7 with a rudimentary 8 th showing. On the 11 th day the eye was well formed, and the colour had changed to dark red, or rather to a mixture of red and blackish brown pigment, darkest in the centres of the ommatidia. The accessory white pigment was also present, particularly around the margin of the ommateum. The eggs hatched on the 12th day, and all the young had black eyes, with the reticulation of the white accessory pigment well developed.

In the second set, as in the first, the same change took place from bright red on the 9 th day to the deeper intermediate red on the 10th, and from that to the dark red on the 11th day, but this stage, owing to the colder weather, lasted for two days and the eggs did not hatch till the 13th day.

Mutant Stock 1.-The original stock, all normal Black-eyed animals, was brought in on June 4th, 1912, and in it the first mutations occurred.

The first to arise was the Red-eye, in which the usual black pigment was replaced by red, the white reticulation and the shape of the eye remaining unaltered.

The Red-eye appeared in the $\mathrm{F}_{2}$ generation from the wild Black, from one female only. This female was first mated with a male from the same brood and had 2 broods, with 7 and 6 survivors respectively. The 7 survivors were 1 Black male, 5 Black females, and 1 Red female; the 6 were 1 Black male, 4 Black females, and again 1 Red female. The female parent was then mated with a Black male just brought in from the ditches, and had a brood of 44 young, 4 of which were Red-eyed. She was put with the first male again and had a brood of 39,3 of which were Red-eyes. With both males, Red-eyed offspring were produced, but these males mated with other females gave only Black-eyed young, and no other instance of a Red-eye appearing has occurred in this stock from then till now. All the Reds of this kind that we have had were derived from 2 heterozygous Black-eyed survivors of this female's third brood.

The Red was mated with Black and proved to be a simple Mendelian recessive. The first $70 \mathrm{~F}_{2}$ broods numbered 1004, 753 Black-eyed and 251 Red-eyed. 
In this mutation the red pigment on hatching is almost invariably a vivid bright red; very occasionally a young one is found with the centres of the eyes of a much darker tint, and still more occasionally one with the whole of the eye of the darker colour. In very old animals the colour tends to darken with age, particularly towards the end of a reproductive period, and brightens after a moult has taken place.

This difference in the intensity of the colour is mentioned here for comparison with Mutant Stock IV, in which similar colour variation has occurred. In Stock IV, however, the different colour variations are heritable.

Two instances of a perfect form without colour, i.e. White-eye, occurred in a brood of the Pure Reds. One, a female, died without mating; the other, a male, mated with an Albino female and gave 1 brood of coloured offspring, 2 Black, 3 Red. Breeding from this brood was carried on for several generations, Black, Red, and Albino reappeared, but no Whiteeye, and the conclusion was reached that the male functioned as a Red-eye, and the white condition in this case was pathological and not heritable.

Three years after the appearance of the Red and after the Stock had been kept for several generations in Laboratory conditions another mutation, the Albino eye, arose. One of the $\mathrm{F}_{2}$ broods from a mating of Pure Black with Pure Red consisted of 7 Black, 1 Red, and 4 Albinos. The total number of offspring from this mating was 745,559 Black, 182 Red, and 4 Albino. Two Albinos, females, survived to maturity, and from these all our Albino stock has been derived. No second case of Albino-eye has arisen independently up to the present time.

In this mutation the eye is degenerate, considerably reduced in size, and very irregular and variable in shape, the eyes in the same animal often differing to a great degree in size and shape, and in the number, size, and arrangement of the lenses of the ommatidia. This imperfection of form is always linked with the absence of retinal colour. The white superficial pigment alone is present, not in a regular reticulation as in the normal eye, but in irregular patches or lumps, with the lenses lying usually around the margin or even beyond it.

The Albino Imperfect eye behaves as a simple recessive to the Coloured Perfect eye. The Albinos carry the colour factor for Pure Black, Black and Red, or Pure Red, but they cannot show colour unless mated with colour. Bred together they give all Albino offspring.

In another mutation, the Nowhite eye, the white superficial pigment is entirely lacking, and the absence of the white behaves as a recessive to its presence.

This mutation arose suddenly in the Coloured Stock after it had been 
kept in Laboratory conditions for two and a half years, both Black Nowhites and Red Nowhites appearing in the $\mathrm{F}_{2}$ from a mating of Pure Black with Pure Red.

The Albino Nowhite or Colourless (see 4) was produced by breeding Coloured Nowhite with Albino. The resultant $\mathrm{F}_{1}$ offispring were normal in appearance, the perfect form and the presence of coloured and of white pigment being dominants. In the $\mathrm{F}_{2}$ the triple recessive appeared, Albino Nowhite, in which the form is imperfect, and both retinal colour and white pigment are lacking. The proportion was 27 Black normal, 9 Black Nowhite, 9 Red normal, 3 Red Nowhite, 12 Albino normal, and 4 Albino Nowhite.

The Nowhite, unlike the other mutations, Red and Albino, has arisen independently many times in our Experimental Stocks and evidently occurs, though very rarely, in different Gammarus species in the wild state. One Nowhite G. pulex and one G. duebenii have been taken.

The white accessory pigment is subject to a good deal of variation and tends to grow thinner with age, breaking up and even partially disappearing in the very old animals.

In one family of this stock a gradual reduction of the white pigment took place from birth to maturity. The eyes were normal at birth, but in four generations not one single survivor reached maturity with the white reticulation normal. From one pair, e.g. 311 young were hatched, 309 with perfectly normal eyes, and 2 with one eye Nowhite; 170 were "spotted," i.e. having spots of white pigment apart from the eye. By the time they became mature, some had only a fleck or two of white left, some had one eye Nowhite and hardly any reticulation in the other eye, while others were completely Nowhite and indistinguishable from typical Pure Nowhites. One of these Gradual Nowhites, an Albino Nowhite female, mated with a Pure Nowhite Black male and hatched a brood of 14 young, all normal Black in appearance with perfect white reticulation.

It is a curious fact that large white "spots" apart from the eye are found on many of the Pure Nowhites which arise suddenly from normal parents (see 6). This is particularly the case when there is any admixture of Albino in the parents' constitution. In the One-sided Nowhites, i.e. those animals with one eye normal and one eye Nowhite, the spots usually occur on the same side as the Nowhite eye, and are very large, much larger than in normal-eyed animals. These spots are usually in definite positions, midway on the head behind the eye, dorsally on the head, or midway on the first peræon-segment over the intestine.

Other mutations to be noted from this stock are the Imperfect Coloured reye, the Blind, and the One-eyed.

The Imperfect Coloured eye differs greatly from the Imperfect Albino 
eye, in that the eye though irregular in shape is not degenerate. The ommatidia present are of normal structure with the retinular cells developed, but the shape of the lenses varies sometimes and the number and arrangement also. In some the number greatly exceeds that of the normal eye, in others it is much below it.

The irregularity of eye appears to be connected with irregularities of development and breeding. The family which produced these abnormal eyes gave rise also to the Blind, the One-eyed, and the Intersexes.

Most of the Intersexes ( $\mathbf{y})$ appeared in the Irregular-eye family, but once four were found in a dredging brought in from the wild after a prolonged drought. The female intersexes show varying degrees of intersexuality, and may be divided into three groups according to the development of their brood-plates and the character of the gnathopod hands.

In all cases in Mutant Stock I the matings have given results in accordance with the simple Mendelian law, and to illustrate the closeness with which the figures obtained by experiment agree with the theoretical expectation the following instances will serve :-

Matings of Blacks carrying Albino-624 young.

$\begin{array}{cccc} & \text { Normal Black. } & \text { Normal Albino. } \\ \text { Theoretical Expectation } & \text {. } & 468 & 156 \\ \text { Experiment } & \text {. } & 468 & 156\end{array}$

Matings of Reds carrying Albino-1879 young.

\begin{tabular}{|c|c|c|}
\hline & Normal Red. & Normal Albino. \\
\hline Theoretical Expectation & · 1408 & 470 \\
\hline Experiment & . 1408 & 471 \\
\hline
\end{tabular}

Matings of Blacks carrying Red, Albino, and Nowhite - 663 young.

Normal Black Normal Red Normal Albino

Black. Nowhite. Red. Nowhite. Albino. Nowhite.

$\begin{array}{ccccccc}\text { Theoretical Expectation } & 278 & 92 & 92 & 30 & 123 & 41 \\ \text { Experiment } & 278 & 93 & 89 & 50 & 118 & 35\end{array}$

Matings of Reds carrying Albino and Nowhite-220 young.

$\begin{array}{ccccc} & \begin{array}{c}\text { Normal } \\ \text { Red. }\end{array} & \begin{array}{c}\text { Red } \\ \text { Nowhite }\end{array} & \begin{array}{c}\text { Normal } \\ \text { Albino. }\end{array} & \begin{array}{c}\text { Albino } \\ \text { Nowhite. }\end{array} \\ \text { Theoretical Expectation } & 124 & 41 & 41 & 14 \\ \text { Experiment } & 127 & 38 & 42 & 13\end{array}$

The Mutant Stocks II, III, and IV originated from three independent Black-eyed pairs from one dredging brought in from the wild in 1922. In all three stocks Red-eyes appeared recessive to Black-eyes. The proof 
that these were different mutations, distinct from each other and from the old Mutant Stock I, was obtained by cross-mating the Red-eyed recessives of all four forms. Whichever way the mating was made the offspring were all Black-eyed, thus settling the matter beyond question.

Mutant Stock II.-Hitherto all the changes had been connected with the eye, and its colour and shape, but in this stock there was a new departure, the White-body mutation, a change in the colour of the body as well (15).

The body-colour of the normal animal is pale green, the female having dark green, almost black gonads and eggs. The eggs as they develop turn yellow and then orange. In the new mutation the whole animal is pearly-white, even to the gonads and eggs. The eggs are so translucent that it is impossible to see them during the whole period of incubation except by transmitted light.

The mutation appeared in the $\mathrm{F}_{2}$ from the wild. An $\mathrm{F}_{1}$ pair of Blackeyed gave in their offspring, normal body Black-eyed; white body Black-eyed, with white gonads and eggs; normal body Reds; and two white body White-eyed, a male and female, the female with white gonads and eggs. This White-eyed female mated with a Red male of the same brood, and gave all White-eyed young, but these young though indistinguishable from each other at birth proved to be of different constitution, viz. Permanent Whites and Changeling Whites. The Permanent or homozygous Whites remain white through life, eyes, body, gonads, and eggs ; but the Changelings develop colour, and by the time they are mature they have all the appearance of normal Reds, that is, green body, dark green gonads and eggs, and bright red eyes (for explanation see 1 17).

The different kinds of animals in this Stock are as follows :-

(1) Black-eyes, normal body-colour, which, mated together, give either (a) all Black, (b) Black and Red, or (c) Black, Red, and White young, according to their constitution ;

(2) Black-eyes, white body, giving Black and White;

(3) Red-eyes, normal body-colour, giving either $(a)$ all Red, or (b) Red and White in the proportion of $3: 1$;

(4) Changelings, which give $(a)$ Red and White in the proportion of $3: 1$ when mated together, $(b)$ Black, Black and Red, or Black, Red and White when mated with the different Blacks, and $(c)$ all Black when mated with recessives from any of the other stocks;

(5) Permanent or homozygous Whites, which give $(a)$ all White when mated together, $(b)$ Black and White when mated with Blacks carrying Red, or with Blacks carrying Red and White, and $(c)$ all Black when mated with Recessives from any of the other stocks. 
When, however, these Permanent Whites are mated with Reds or Changelings of their own stock we get the remarkable result that the reciprocal crosses are quite different; thus, any Red male of the stock mated with a homozygous White female (white gonads) gives all Whiteeyed young, consisting of Whites and Changelings; but the reciprocal cross homozygous White male by Red female (dark gonads) gives either all Red-eyed young if the female is Pure Red, or Reds and Whites if the Red female carries White. Similarly White male by Changeling female (dark gonads) gives half Reds and half Whites (the actual figures are 131 Reds, 130 Whites), whereas the reciprocal cross, Changeling male by White female, gives all White-eyed young consisting of Whites and Changelings.

Mutant Stock III.-This is the only stock so far in which we have found "mosaic" eyes, i.e. eyes with some of the ommatidia black and some bright red. This stock differs from the three others described in that the Red-eye mutation did not arise suddenly, but developed gradually in the $\mathrm{F}_{2}$ generation. In two of the $\mathrm{F}_{1}$ families some of the Black-eyed became reddish black as they matured and produced some Red-eyed offtspring.

To take an instance from each family : in one brood of the first family, of the 5 survivors, 4 had become Reddish-black and 1 was still jet-black. This Black, a male, mated with a Reddish-black, gave 30 Black and 13 Reddish-black; only 3 of the 30 survived and all 3 developed the reddish tinge. Two of the Reddish-blacks were mated, and gave 17 Black, 11 Reddish-black, and 2 Dark Red. The female of this pair, mated in the brood-bowl, had 6 young, 5 Black and 1 with the left eye of the curious " mosaic " type mentioned above.

In the second family one Reddish-black became redder as it matured, and its left eye developed into a typical mosaic eye with almost as many bright red ommatidia as black. One pair of this family had 255 young, of which 224 appeared to be Black, 13 Reddish-black, 13 Dark Red, 3 Intermediate, and 2 Bright Red.

The eye-colours in this stock are not only very difficult to define at birth, but are so subject to change with growth that it is almost impossible to give the actual figures of the different kinds with any certainty.

Black is closely allied to Reddish-black (Black with a distinct reddish tinge) and Reddish-black to Dark Red (dark brownish-black in the centres of the ommatidia and red around the margins); but some Blacks remain black and others develop the reddish tinge; some Reddish-black are unchanged, others become Dark Red; some Dark Reds never alter, others lighten a little in colour and lose the brownish tint, and others again become completely red.

Mutant Stock $I V$.- The stock is particularly interesting as having 
in addition to the Black three distinct kinds of Red-eyes, a Bright Redeye, with the usual brilliant scarlet pigment; an Intermediate Red like the second stage in the eye-colour of the embryo (p. 46); and a very dark Red almost black, like the last stage of the embryo before hatching. The exceptional feature of the last is that the dark red colour lightens as the animal grows older. Sometimes the eye becomes a brilliant red, indistinguishable from the Bright Red-eye, at other times the periphery of the eye lightens, and the centre remains dark. But however great the change may be in the colour of the eye, the constitution of the animals remains unaffected, for those which have lost all the dark pigment, and those which have retained the most of it, give the same results in the offspring.

\section{Crossing Gammarus Species.}

Attempts have been made from time to time in the Laboratory to cross the various species under observation, but although a certain measure of success has been reached in so far that some of the animals mated and laid eggs, yet up to the present the net result is failure; no young have been hatched from a cross. The bars to cross-breeding distinct species appear to be, and probably are, insuperable, though that perhaps is a point on which one ought not to speak definitely without further experiment.

The greatest difficulty to be encountered is the different development of the various species, the size, growth stages, breeding habits, length of the breeding periods, and the incubatory periods, and so on. Other differences, of habitat and salinity for example, can be overcome, provided only that sufficient time is taken in changing the conditions, while bringing salt-water species to fresh water and vice versa. The marine species need a much larger amount of oxygen than either fresh water or brackish, so that it is necessary at first to use with them an air-circulation system, though this may be dispensed with gradually.

Each of the species used in the experiments was divided into three stocks, one stock brought to live in fresh water, one in brackish, and one in sea-water. As a general rule the females were kept to their own waters, and the males subjected to the change of condition, for instance in the crosses $G$. Chevreuxi brackish, with $G$. pulex fresh water, the males were taken from the Chevreuxi stock which had been kept for several generations in fresh water.

The species used in the experiments were $G$. locusta, marine; $G$. marinus, marine, littoral; G. Chevreuxi and $G$. duebenii, brackish, from a salt marsh; another brackish water species, not yet named, from brackish pools at Cawsand within the tidal zone; and G. pulex, fresh water, rivers and streams. 
The results are briefly as follows :-

No matings were obtained from the undermentioned crosses.

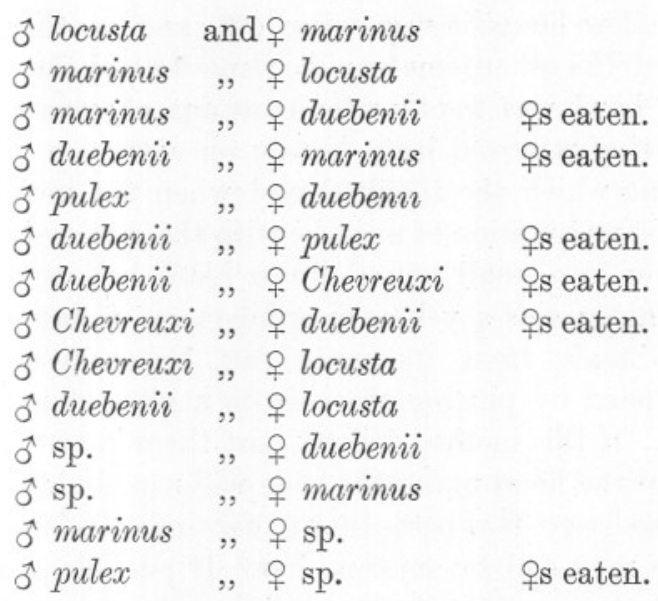

In the cross $\hat{o} s p$. and $q$ pulex in fresh water, 7 males and 14 females were used ; 4 females paired, 1 twice, no eggs were laid; all the females eaten.

In the cross 0 sp. and + Chevreuxi, 144 males and 229 females were tried in the brackish-water experiments, 2 pairings took place, 1 lasting 10 days, no eggs were laid. In the fresh-water experiments 6 males and 12 females were used, no mating; all the females eaten.

The reciprocal cross - 259 ơ Chevreuxi and 201 ㅇ sp. in brackish waterwas successful in that 27 matings occurred, and eggs were laid in six cases, 4 females carried them $9,6,13$, and 18 days respectively before throwing them off. Two males and 6 females were used in the fresh-water experiment; 2 matings; and eggs laid.

The cross, ot pulex and 우 Chevreuxi, fresh water, 22 males and 35 females, resulted in 5 pairs mating; no eggs laid.

The reciprocal crosses were made with 104 o Chevreuxi and 44 o pulex in fresh water ; 15 females mated, 5 batches of eggs were laid, one female mated 4 times; one 3 times, laid eggs and was eaten; one mated for 7 days, laid eggs, carried them for 13 days, mated again for 3 days, no eggs, mated again for 13 days, no eggs, mated again and was eaten. Another female mated for 10 days, no eggs; again for 11 days, eggs laid and carried for 18 days ; mated again and eggs, carried for 13 days ; mated again and eggs once more.

In the experiments referred to above the method of mating was as follows: several ovigerous females of the one species were taken, and kept in a bowl without a male until the eggs were within a day or two 
of hatching, and the females therefore in the right physiological condition for mating. A paired male of the other species was then separated from its mate, and placed in the bowl with all the females. If it did not pair within a few hours it was taken out, and another male tried. If this one paired, the other females were removed and the pair left to themselves. The bowl was kept under constant observation, the female's own brood being removed immediately on extrusion and a note made of the time at which she moulted and when the new eggs were laid. There could be no question of mistake with the matings done in this way. New eggs show as a small round almost black ball in the middle of the pouch, ripening eggs as a yellow or orange mass filling the whole pouch. Separating a male from its mate can be easily done before the brood is extruded by putting the pair on a glass slide and draining all the water off. If this method fails to part them in two or three seconds, the warmth of the hand under the slide will usually effect it; but if the male refuses to let go, it is better not to continue too long as the struggles of the female may end by injuring her. If possible, a male which has moulted some days previously should be used. A male which has only just accomplished its moult is a great danger even to its own species, as at such a time it is more voracious than usual, and if the female moults while it is still hungry there is little chance of her escaping.

\section{BIBLIOGRAPHY.}

1. 1913. Sexton, E. W. Description of a New Species of Brackishwater Gammarus (G. chevreuxi, n.sp.). Journ. Mar. Biol. Assoc., IX, No. 4. 1913.

2. 1913. Sexton, E. W., and Matthews, A. Notes on the Life History of Gammarus chevreuxi. Journ. Mar. Biol. Assoc., IX, No. 4. 1913.

3. 1916. Sexton, E. W., and Wing, M. B. Experiments on the Mendelian Inheritance of Eye-colour in the Amphipod, Gammarus chevreuxi. Journ. Mar. Biol. Assoc., XI, No. 1, March. 1916.

4. 1917. Allen, E. J., and Sexton, E. W. The Loss of the Eyepigment in Gammarus chevreuxi. Journ. Mar. Biol. Assoc., Vol. XI, No. 3. 1917.

5. 1917. Allen, E. J. Heredity in Plants, Animals, and Man. Journ. Mar. Biol. Assoc., XI, No. 3. Dec., 1917.

6. 1920. Allen, E. J., and Sexton, E. W. Eye-colour in Gammarus. Journ. Genetics, IX, No. 4. March, 1920. 
7. 1921. Sexton, E. W., and Huxley, Julian S. Intersexes in Gammarus Chevreuxi and Related Forms. Journ. Mar. Biol. Assoc., XII, No. 3. Sept., 1921. (Plate I, "Immature Normal male," should be "Young male, growth stage 9, last moult before the definitive adult characters are attained.")

8. 1921. Huxley, J. S. Linkage in Gammarus chevreuxi. Journ. Genet., XI, No. 3. Dec., 1921.

9. 1923. Huxley, J. S. Further Data on Linkage in Gammarus chevreuxi, and its Relation to Cytology. Brit. Journ. Exp. Biol., Vol. I. Oct., 1923.

10. 1924. Huxley, J. S. Practical Biology. School Science Review, No. 21. Sept., 1924.

11. 1924. Sexton, E. W. The Moulting and Growth-stages of Gammarus, with Descriptions of the Normals and Intersexes of G. chevreuxi. Journ. Mar. Biol. Assoc., XIII, No. 2. Nov., 1924.

12. 1925. Chevreux, Ed. ex Louis Fage. Faune de France: 9 : Amphipodes, pp. 255-256. Paris, 1925.

13. 1925. Palmer, Richard. The Chromosome Complex of Gammarus chevreuxi, Sexton. Nature. Nov. 28, 1925.

14. 1925. Huxlex, J. S., and Ford, E. B. Mendelian Genes and Rates of Development. Nature. Dec. 12, 1925.

15. 1926. Sexton, E. W., and Clark, A. R. New Mutations in Gammarus chevreuxi Sexton. Nature. Feb. 6, 1926.

16. 1926. Palmer, Richard. The Chromosome Complex of Gammarus chevreuxi Sexton. I. Spermatogenesis. Quart. Journ. Microscopical Science, Vol. 70, Part III. Sept., 1926.

17. 1927. Sexton, E. W., and Pantin, C. F. A. Inheritance in Gammarus chevreuxi Sexton. Nature. Jan. 22, 1927. 
